\title{
The Power of Presence: The Role of Mindfulness at Work for Daily Levels and Change Trajectories of Psychological Detachment and Sleep Quality
}

\author{
Ute R. Hülsheger \\ Maastricht University
}

\author{
Jonas W. B. Lang \\ Ghent University
}

\author{
Franziska Depenbrock, Carmen Fehrmann, \\ Fred R. H. Zijlstra, and Hugo J. E. M. Alberts \\ Maastricht University
}

\begin{abstract}
In this research, we examined the role of mindfulness for recovery from work using a daily diary design ( $N=121 ; 5$ days; 3 measurement occasions per day). The first goal of the study was to investigate the relationship of mindfulness with sleep quality and the mediating role of psychological detachment from a day-level perspective. A second goal was to extend the process perspective in recovery research beyond the day level and consider systematic change trajectories in recovery variables over the course of the work week and the role of mindfulness in these trajectories. Results regarding day-level relationships confirmed that mindfulness experienced during work was related to subsequent sleep quality, and this relationship was mediated by psychological detachment from work in the evening. Furthermore, an investigation of the role of mindfulness in recovery change trajectories supported the idea that psychological detachment trajectories increase over the work week for individuals low on mindfulness while there was no systematic mean-level change for individuals high on mindfulness. In contrast, sleep quality followed a linear increase from Monday to Friday for all individuals, irrespective of their levels of trait mindfulness. Practical and theoretical implications for the mindfulness and the recovery literature are discussed in conclusion.
\end{abstract}

Keywords: mindfulness, recovery, well-being, diary study, sleep

Do not dwell in the past. Do not dream of the future. Concentrate the mind on the present moment.

—Buddha

Industrial and organizational psychologists have extended traditional occupational health research by studying how employees recover from work and replenish their resources during their leisure time. Two key elements of successful recovery are psychological detachment and sleep. Detachment is of interest because researchers have suggested that insufficient detachment from work and rumination during nonwork time causes a mental continuation of work stressors (Querstret \& Cropley, 2012; Sonnentag, Binnewies, \& Mo-

This article was published Online First September 8, 2014.

Ute R. Hülsheger, Department of Work and Social Psychology, Faculty of Psychology and Neuroscience, Maastricht University; Jonas W. B. Lang, Department of Personnel Management, Work and Organizational Psychology, Faculty of Psychology and Educational Sciences, Ghent University; Franziska Depenbrock, Carmen Fehrmann, and Fred R. H. Zijlstra, Department of Work and Social Psychology, Faculty of Psychology and Neuroscience, Maastricht University; Hugo J. E. M. Alberts, Department of Clinical Psychological Science, Faculty of Psychology and Neuroscience, Maastricht University.

Correspondence concerning this article should be addressed to Ute R. Hülsheger, Department of Work and Social Psychology, Faculty of Psychology and Neuroscience, Maastricht University, P.O. Box 616, 6200 MD Maastricht, the Netherlands. E-mail: ute.hulsheger@maastrichtuniversity.nl jza, 2008). This process typically results in continued psychophysiological activation during nonwork time and thereby impedes recovery (Meijman \& Mulder, 1998; Querstret \& Cropley, 2012). While insufficient detachment primarily affects the time immediately after work, nighttime sleep also plays a central role in the recovery process, in that it has restorative functions and helps employees to replenish their resources (Querstret \& Cropley, 2012; Sonnentag et al., 2008). Sleep is vital to every human, and sleep quality and sleep loss affect quality of life and mood and even affect mortality (Groeger, Zijlstra, \& Dijk, 2004; Hublin, Partinen, Koskenvuo, \& Kaprio, 2007; Minkel et al., 2012). Sleep also has direct effects on work behavior and performance. For instance, Kessler et al. (2011) identified a prevalence rate of insomnia of $23.3 \%$ and significant associations between insomnia and performance of U.S. workers. They further estimated that work-related insomnia leads to reductions in work performance that accumulate to productivity losses of $\$ 63.2$ billion a year.

Recovery research has conceptualized recovery as a process in which employees pass through consecutive psychological states during the transition from work to leisure time (Geurts \& Sonnentag, 2006; Meijman \& Mulder, 1998; Zijlstra, Cropley, \& Rydstedt, 2014). Extant recovery research typically incorporates this process perspective by studying within-person correlations or regressions in recoveryrelated variables within days. In our current research, we contribute to the recovery literature by extending the process perspective on recovery in two ways.

Our first contribution is that we studied the idea that mindfulness-a positive psychological state that can be experienced dur- 
ing work-facilitates the recovery process by promoting psychological detachment after work and subsequent sleep quality. Mindfulness is a state of consciousness in which individuals pay attention to the present moment with an accepting and nonjudgmental attitude (Brown, Ryan, \& Creswell, 2007; Kabat-Zinn, 1994). Recently, researchers have started acknowledging the potential salutary effects of mindfulness for employee well-being (e.g., Allen \& Kiburz, 2012; Glomb, Duffy, Bono, \& Yang, 2011; Hülsheger, Alberts, Feinholdt, \& Lang, 2013). In the present work, we built upon the mindfulness literature and integrated it into recovery research. Learning more about positive work-related experiences that facilitate rather than impede daily recovery may be vital when it comes to developing workplace health intervention programs aimed at maintaining a healthy workforce and enabling sustainable employment.

A second way in which this research contributes to the literature is by extending the process perspective in recovery research beyond the day level. Like earlier researchers, we also studied day-level effects to understand the transition from daily work to daily recovery periods as part of our first contribution. However, we also extended this perspective by adding the notion that recovery effects may also change over the course of several days and display systematic change patterns across the work week. Traditionally, recovery researchers have either not considered withinperson and between-person fluctuations across days or treated them as a source of error variance. However, theoretical advances on entrainment (Ancona, Okhuysen, \& Perlow, 2001) and research on cyclical patterns in affective states (Beal \& Ghandour, 2011; Larsen \& Kasimatis, 1990; Watson, 2000) suggest that withinperson variability of recovery-related constructs across days may be a function of the day of the week. The purpose of our research was therefore to contribute to a better understanding of week-level change patterns in recovery processes by studying change trajectories in psychological detachment and sleep quality and the role of trait mindfulness in explaining individual differences in these change trajectories.

Identifying weekly cycles of sleep quality and psychological detachment and individual differences therein has both scientific and practical implications. High psychological well-being may not only be indicated by high overall levels of sleep quality and psychological detachment on a given day but also by stable levels of sleep quality and detachment in terms of reduced cyclical variation over the workweek. Investigating which factors reduce cyclical variation in sleep quality and detachment is therefore important in order to gain a comprehensive understanding of the recovery process.

\section{Mindfulness}

The key element of mindfulness is attention. By training regulation of attention, mindfulness promotes awareness of the continuous stream of internal (e.g., thoughts and emotions) and external (e.g., sounds and events) experiences that occur in the present moment (Brown et al., 2007; Germer, 2005). It is about paying full attention to these external events and internal thoughts, feelings, and sensations with a nonjudgmental attitude of curiosity and acceptance (Baer, 2003). In this way, the ability to observe rather than to identify with thoughts and emotions is strengthened, a process labeled cognitive decentering (Bishop et al., 2004). Con- sequently, mindfulness enhances the ability to make a distinction between direct experiences and the mental story or interpretation of these experiences, thereby reducing their potentially harmful impact on well-being.

In scientific psychology, researchers have been interested in different aspects of mindfulness and have studied the construct of mindfulness from different angles: In clinical psychology, researchers have mainly focused on how mindfulness can be increased with mindfulness-based treatment programs (Kabat-Zinn, 1982, 1990; Kristeller, Baer, \& Quilian-Wolever, 2006; Segal, Williams, \& Teasdale, 2002) and have studied the salutary effects of these interventions in both clinical and nonclinical populations (Bohlmeijer, Prenger, Taal, \& Cuijpers, 2010; Chiesa \& Serretti, 2009; Davis \& Hayes, 2011; Grossman, Niemann, Schmidt, \& Walach, 2004). In personality psychology, researchers have considered mindfulness as a natural state of mind that can be attained by individuals without meditation experience or experience with mindfulness-based interventions. In this line of research, the focus lies on natural variations in mindfulness within and between persons, and it has consequently been studied from a trait and a state perspective (e.g., Brown \& Ryan, 2003; Niemiec et al., 2010; Weinstein, Brown, \& Ryan, 2009). Although lying dormant for many years, mindfulness research has also started to surge in industrial and organizational psychology in recent years. All three conceptualizations of mindfulness have been embraced: Researchers have studied mindfulness-based interventions (Hülsheger et al., 2013; Wolever et al., 2012), trait variations in mindfulness (Allen \& Kiburz, 2012; Hülsheger et al., 2013; Marzuq \& Drach-Zahavy, 2012; Reb, Narayanan, \& Chaturvedi, 2014), and-to a lesser extent—mindfulness as a state (Hülsheger et al., 2013). These studies have provided initial evidence on the beneficial effects of mindfulness in the work context: for employee health and wellbeing (Allen \& Kiburz, 2012; Hülsheger et al., 2013; Marzuq \& Drach-Zahavy, 2012), for employee engagement (Leroy, Anseel, Dimitrova, \& Sels, 2013), performance (Dane \& Brummel, 2014; Reb, Narayanan, \& Ho, 2013; Zhang, Ding, Li, \& Wu, 2013), and leadership effectiveness (Reb et al., 2014).

\section{Mindfulness and Sleep Quality From a Day-Level Perspective}

The link between mindfulness and sleep quality is well established in the mindfulness literature. The majority of work in this area has been conducted in clinical contexts, where studies provided evidence that mindfulness-based treatment programs are effective in treating clinical levels of insomnia (Gross et al., 2011; Heidenreich, Tuin, Pflug, Michal, \& Michalak, 2006; Ong, Ulmer, \& Manber, 2012) and alleviate sleep-related problems that often go along with other physical and psychological illnesses such as cancer or substance abuse (Carlson \& Garland, 2005; Shapiro, Bootzin, Figueredo, Lopez, \& Schwartz, 2003). In nonclinical contexts, cross-sectional studies investigating trait mindfulness rather than mindfulness-interventions have established a link with sleep quality in psychology students (Howell, Digdon, \& Buro, 2010; Howell, Digdon, Buro, \& Sheptycki, 2008).

In the context of work, research in this area is still scarce. Initial evidence on the beneficial effects of mindfulness for working adults stems from two studies investigating the effect of workplace mindfulness-based interventions on sleep quality. While Wolever 
et al. (2012) found that participants in the mindfulness intervention group showed improvements in sleep quality that were significantly different from those in a control group, Klatt, Buckworth, and Malarkay (2009) observed improvements in the intervention group that were, however, similar to those found in the control group. A third study examined the relationship between trait mindfulness and sleep quality in a cross-sectional survey study with working parents (Allen \& Kiburz, 2012). Although these studies provided valuable first insights into the role of mindfulness in fostering recovery and promoting sleep quality of working adults, important questions still remain unanswered.

First, while these studies established the link between mindfulness and sleep quality, they did not provide any insights into the mechanisms driving this relationship in the working population. Extant work on the mindfulness-sleep quality relationship in the clinical area has highlighted the role of sleep-related arousal (Ong et al., 2012) and dysfunctional sleep-related cognitions and beliefs (Heidenreich et al., 2006). The mechanisms underlying the mindfulness-sleep quality relationship in nonclinical, working populations are, however, likely to differ from the mechanisms driving the relationship in clinical populations with clinical levels of insomnia. We therefore investigated psychological detachment from work as a potential underlying mechanism.

Second, extant studies have focused on trait aspects of mindfulness and analyzed how between-person differences in mindfulness (occurring either naturally or through training) relate to between-person differences in sleep quality assessed retrospectively at one point in time. Yet, the theoretical and empirical mindfulness literature suggests that mindfulness does not only have trait-like but also state-like properties (Glomb et al., 2011; Weinstein et al., 2009) and so does sleep quality (Rook \& Zijlstra, 2006; Sonnentag et al., 2008; Sonnentag \& Binnewies, 2013; Walkowiak, Hülsheger, \& Zijlstra, 2010. Indeed, day-to-day within-person variation in mindfulness has been shown to be substantial, ranging between $38 \%$ and $71 \%$ (Brown \& Ryan, 2003; Hülsheger et al., 2013). Similarly, around $60 \%$ of variation in sleep quality lies within persons (Sonnentag \& Binnewies, 2013; Walkowiak et al., 2010). To date, little is known about how these daily, within-person variations in mindfulness during work directly relate to subsequent sleep quality. Yet, for a comprehensive understanding of the functioning of mindfulness, it is important to learn more about the processes that occur at the most basicnamely, the intrapersonal-level. Psychological constructs may reflect distinct phenomena and function differently at different levels of analyses (e.g., the between-person and the within-person level; Bliese \& Jex, 2002; Ilies, Scott, \& Judge, 2006; Judge, Hulin, \& Dalal, 2012). Researchers have therefore argued for the necessity to systematically investigate whether relationships between constructs are similar or differ across levels (Chen, Bliese, \& Mathieu, 2005). The question is whether an aggregate construct at the between-person level (here, the average level of mindfulness across days) is more than the sum of its lower level counterpart at the within-person level (here, daily levels of mindfulness; Bliese \& Jex, 2002). Finding that relationships at the between-person level differ significantly from the respective relationships at the withinperson level suggests that processes are emergent (researchers then speak of an emergent or contextual effect). If they do not differ across levels, this suggests that relationships are isomorphic across levels (for a detailed discussion, see Bliese \& Jex, 2002; Hofmann
\& Gavin, 1998). Goal in the present study was therefore to systematically test whether the mindfulness-sleep quality relationship is characterized by emergent or isomorphic processes by investigating relationships at the between-person and within-person levels simultaneously in a multilevel study.

In sum, with the present study, we sought to build upon and extend previous work on mindfulness and sleep quality: First, we shed light on the (work-related) underlying mechanisms by investigating psychological detachment after work as a mediator. Second, we adopted a diary design that (a) allows for an ecologically valid assessment of daily levels of sleep quality, mindfulness, and psychological detachment and (b) allows systematic investigation of relations among mindfulness, detachment, and sleep quality at both the within-person and between-person level.

\section{The Mediating Role of Psychological Detachment}

By promoting a focus on the present moment, mindfulness facilitates healthy self-regulation and detachment from work during off-work time. With a present-moment orientation, we are aware of what is happening right here, right now. We realize what is going on in our surroundings and at the same time notice internal sensations, thoughts, and emotions. When individuals are mindful, they thus refrain from dwelling on the past or worrying about the future and pay attention to the present moment instead. Being able to maintain such a state of mind facilitates psychological detachment from work, defined as an "individual's sense of being away from the work situation" (Etzion, Eden, \& Lapidot, 1998, p. 579) and "not being involved in work-related feelings or thoughts" (Fritz, Yankelevich, Zarubin, \& Barger, 2010, p. 977) during non-work time. Naturally, individuals who tend to focus on the present moment rather than on the past or the future are less involved with work-related issues during non-work time.

Furthermore, mindfulness researchers have suggested that mindful awareness of present-moment experiences is per definition nonconceptual in nature (Brown et al., 2007). Put differently, while focusing on the present-moment, one simply notices what is happening without interfering with this experience by reflecting upon or evaluating these internal or external experiences. This phenomenon has also been referred to as re-perceiving (Shapiro, Carlson, Astin, \& Freedman, 2006) or cognitive decentering (Bishop et al., 2004), describing a separation of the self from experiences, events, and mental processes (Glomb et al., 2011). By promoting a present-moment orientation, mindfulness helps individuals observe external events and internal thoughts and emotions from the perspective of an uninvolved bystander who simply notices what is going on with a nonjudgmental attitude. An employee who has made a mistake at work might interpret it as a signal of his inadequacy and might worry about his supervisor's evaluation of his competence and about the consequences of the mistake for his future career. The appraisal of the situation thus creates stress and tension, rather than the situation itself. Mindfulness promotes the opposite, namely, a present-oriented awareness and a nonjudgmental attitude, and thereby creates a separation between the ego and internal and external events (Glomb et al., 2011). As Shapiro et al. (2006) put it: "We experience what is instead of a commentary or story about what is" (p. 379). Being mindful at work thus facilitates adaptive stress appraisal (Weinstein et al., 2009) and thereby helps employees cope with work 
stressors and demands more effectively (cf. Hülsheger et al., 2013). They are likely to experience more positive and less negative affective reactions at work, to recover faster from negative work events (Glomb et al., 2011), and may consequently be less troubled by work issues that might spill over to their non-work time. This idea is supported by fundamental experimental research showing that participants who were encouraged to attend to their emotions in an accepting way while writing about an ongoing stressful experience showed better heart rate habituation than participants in control groups (Low, Stanton, \& Bower, 2008). Taken together, these arguments and findings suggest that mindfulness facilitates psychological detachment from work.

Psychological detachment in turn is related to sleep quality. Researchers have argued that insufficient detachment from work and rumination during non-work time causes a mental continuation of work demands and work stressors and thereby impedes successful recovery (Querstret \& Cropley, 2012; Sonnentag et al., 2008). This results in continued psychophysiological activation during non-work time that hinders sleep (Querstret \& Cropley, 2012). Empirically, the link of psychological detachment/work-related rumination with sleep quality has been established both in crosssectional and longitudinal studies (Åkerstedt, Nordin, Alfredsson, Westerholm, \& Kecklund, 2012; Cropley, Dijk, \& Stanley, 2006; Querstret \& Cropley, 2012). We therefore hypothesized mindfulness to be related to daily sleep quality and expected psychological detachment from work to play a mediating role.

Hypothesis 1: Mindfulness during work is positively related to (a) psychological detachment from work during non-work time and (b) sleep quality.

Hypothesis 2: The relationship between mindfulness during work and sleep quality is mediated by psychological detachment from work during non-work time.

\section{Extending the Process Perspective by Considering Change Patterns Across the Work Week}

In the recovery literature, researchers have investigated psychological detachment and sleep quality as fluctuating phenomena and have consequently adopted event-sampling and diary methodology in their research (e.g., Rook \& Zijlstra, 2006; Sonnentag et al., 2008). In the vast majority of these studies, analyses focused on within-person relationships within days. These within-person event-sampling and diary studies were very valuable in that they shed light on relationships between ecologically valid, repeated measures of fluctuating states within days. However, there is a scarcity of research on systematic week-level variation and day of the week effects in recovery-related variables. Goal of the present study is therefore to extend the process perspective in recovery research by investigating systematic change patterns in psychological detachment and sleep quality across the workweek and how mindfulness influences these change patterns.

In doing so, we adopted Beal and Ghandour's (2011) reasoning on dynamic aspects of affective experiences at work and applied it to psychological detachment and sleep quality. Accordingly, we argued that detachment and sleep quality can be decomposed into four different components: (a) a person's mean or trait level of detachment and sleep quality; (b) change trajectories in detach- ment and sleep quality (i.e., systematic daily variation around a person's mean level over time that is a function of the day of the week [also referred to as cyclical variation]); and (c) affective events at work may explain deviations from these change trajectories. We added a fourth component: (d) interindividual differences that explain interindividual deviations from systematic change trajectories. In the present endeavor, we focused on the second and on the fourth component: First, we aimed at detecting systematic change patterns in detachment and sleep quality across the work week, and second, we investigated whether individual differences in trait mindfulness explain deviations from these change patterns. Specifically, we expected individuals high on mindfulness to experience less systematic change in psychological detachment and sleep quality than individuals low on mindfulness.

Going beyond an investigation of the predictors of momentary levels of psychological detachment to study systematic change in psychological detachment and sleep quality over the work week provides valuable new insights into the recovery process: Apart from overall levels of detachment and sleep quality, the stability versus variability of these variables may be indicative of employee health and well-being. Two persons may have the same overall level of sleep quality when looking at the average level of sleep quality across the work week, but Person A may display systematic changes in sleep quality depending on the day of the week while Person B's sleep quality and detachment may remain at a constant level over the work week. It is therefore important to learn more about factors that promote stability of recovery-related variables, as prior research has suggested that stability in affect-related variables is associated with psychological health and well-being (Gruber, Kogan, Quoidbach, \& Mauss, 2013).

\section{Change Trajectories in Psychological Detachment and Sleep Quality}

We expected to find that psychological detachment and sleep quality do change over the course of a regular (Monday-to-Friday) work week. This assumption is grounded in theoretical advances on entrainment and on research on cyclical patterns in affective states. The concept of entrainment describes the synchronization of human activities with other processes in terms of pace, cycle, or rhythm (Ancona et al., 2001). Entrainment has been used to explain how variation in daily moods displays a periodicity that corresponds to our 7-day week (Larsen \& Kasimatis, 1990). Accordingly, cyclical variation in daily moods is aligned (entrained) with the 7-day week, which accounts for a lot of the variance in daily moods. The 7-day week is a temporal organization that has a strong organizing influence on people's lives (Larsen \& Kasimatis, 1990). The week is a socially constructed environment that-for most people_consists of an infinite loop of 5 days of work (Monday through Friday) and 2 days off (Beal \& Ghandour, 2011). This framework provides structure, routine, and predictability to our lives and guides our activities (e.g., working Monday through Friday, shopping on Saturday, family and social activities on Saturday and Sunday; Larsen \& Kasimatis, 1990). Larsen and Kasimatis (1990) consequently argued that "events that are associated with days of the week, . . . should also be cyclical in nature" (p. 164). We therefore posited that psychological detachment from work and, in consequence, sleep quality are also subject to the 
organizing power of the 5-day work week and therefore follow a general change trajectory.

With regard to the specific pattern of change across a 5-day Monday-through-Friday work week, extant research and theories lead to divergent predictions: Building on the effort-recovery model (Meijman \& Mulder, 1998), one might argue that exposure to work demands and associated depletion of an employee's resources as well as psychological and physiological reactions accumulate over the course of the work week. As a consequence of this accumulation of effort expenditure, psychological detachment and sleep quality may be highest after the weekend respite and follow a linear decline from Monday through Friday. On the other hand, researchers have highlighted the role of anticipation of work demands in the recovery process and argued that especially in the beginning of the work week, employees worry about the demands, challenges, and potential problems that lie ahead of them (Rook \& Zijlstra, 2006). As the week progresses, one is able to complete job tasks and tackle problems. In consequence, psychological detachment and sleep quality may be lowest on Monday and show a linear increase from Monday through Friday. With regard to sleep quality, the study by Rook and Zijlstra (2006) provided a first indication that sleep quality may indeed increase over the course of the work week: An inspection of their plot of mean sleep quality levels by the day of the week suggests increasing levels of sleep quality. However, they did not statistically test change trajectories, which was the goal in the present study. Given these opposing viewpoints, we therefore present two contrasting hypotheses:

Hypothesis 3: Psychological detachment changes over the course of the workweek. It displays (a) a linear decrease from Monday through Friday. It displays (b) a linear increase from Monday through Friday.

Hypothesis 4: Sleep quality changes over the course of the work week. It displays (a) a linear decrease from Monday through Friday. It displays (b) a linear increase from Monday through Friday.

\section{Mindfulness Moderates Change Trajectories in Psychological Detachment and Sleep Quality}

In the previous section, we argued that due to the strong organizing aspects of the work week, there might be a general pattern of change in psychological detachment and sleep quality over the course of the work week. Thus, on average, a pattern of decreasing or increasing mean levels is likely to be observed for the entire sample of employees. However, extant research in the area of mood and affect suggests that individuals are likely to differ in the extent to which they are susceptible to effects of entrainment. For instance, cyclical effects of mood have been shown to be stronger for introverts than for extraverts (Larsen \& Kasimatis, 1990). We therefore posited that mindfulness functions as an individualdifferences variable that explains interindividual differences in mean-level change trajectories for psychological detachment and sleep quality. Specifically, we expected effects of entrainment to be weaker for individuals with high levels of mindfulness compared with their counterparts with low levels of mindfulness.

As argued earlier, a core element of mindfulness is a presentmoment orientation that helps one to accept oneself and the sur- rounding circumstances (positive and negative ones) and encourages the savoring of present-moment experiences (Brown, Kasser, Ryan, Linley, \& Orzech, 2009). Individuals high on mindfulness tend to experience the present moment rather than reflecting on the past or imagining the future. They are thus less likely to be influenced by what they did or what has happened on previous days or by the anticipation of potential future events and experiences. Entrainment of psychological detachment and sleep quality to the work week should therefore be weak for individuals high on mindfulness: They should neither be troubled by accumulating work demands and an increasing inability to detach (cf. Hypothesis 3a) nor have a strong desire for the weekend to come in order to release them from their preoccupation with upcoming work demands (cf. Hypothesis $3 b$ ). We therefore expected that effects of entrainment are weaker for employees high on mindfulness and that they display less systematic mean-level change in psychological detachment and sleep quality over the course of the work week than employees low on mindfulness.

Hypothesis 5: Mindfulness explains individual differences in change trajectories of (a) psychological detachment and (b) sleep quality: Psychological detachment and sleep quality show stronger systematic changes (decreases or increases) over the course of the work week for individuals low on mindfulness than for individuals high on mindfulness.

\section{Method}

\section{Sample and Procedure}

Participants were recruited from a variety of organizations and occupations in Germany by the third and fourth authors using a combination of recruitment methods: First, the snowballing technique was employed, which is frequently used in organizational research (Gosserand \& Diefendorff, 2005; Grandey, Fisk, \& Steiner, 2005; Groth, Hennig-Thurau, \& Walsh, 2009): The recruitment team approached working adults from their own network, who in turn recruited individuals they knew to participate in the study. Second, strangers were recruited individually at their workplaces- for instance, local pharmacies, book stores, schools, and kindergartens. Third, participants were recruited at a local job fair. The study was introduced broadly as a study on workplace well-being, without further mention of the topics of recovery, sleep quality, or mindfulness. Overall, 158 paper-and-pencil survey packages were distributed to employees working in a variety of occupations who had signed up to participate in the research. As an incentive to participate in the study, participants were offered feedback on study results after completion of data collection. No monetary compensation or other incentives were offered.

Participants who had expressed their interest in participating in the study received a paper-and-pencil survey package consisting of a general questionnaire and the diary booklet, covering three daily surveys (a morning, an end of work, and a bedtime survey) over 5 workdays. Participants were instructed to complete the general questionnaire before starting with the daily diary surveys. After completion, questionnaires and diary booklets were either returned by mail or collected by the recruitment team.

Participants were instructed to complete surveys at the indicated time frames (i.e., after getting up, end of work, and bedtime) and 
to rather leave out a daily survey than to fill it in retrospectively. In order to be able to get an indication at what times participants completed the daily surveys, we asked them to report the date and time of filling in every individual survey. An inspection of these dates and times indicated that participants complied with study instructions to fill in the respective surveys at different time points: On average, $9 \mathrm{hr} 38 \mathrm{~min}(S D=2.09 \mathrm{hr})$ lay between filling in the morning and end-of-work surveys and $5 \mathrm{hr} 36 \mathrm{~min}(S D=2.03 \mathrm{hr})$ lay between filling in end-of-work and bedtime surveys.

A total of 121 valid questionnaires were returned, resulting in a response rate of $77 \%$. Participants $(66.7 \%$ Female, $33.3 \%$ male) had a mean age of 42 years $(S D=12.7$ years), an average tenure of 11.9 years $(S D=10.03$ years), and on average worked $39 \mathrm{hr}$ per week. The sample comprised a broad range of professions: Twenty percent of participants were teachers (nursery school, elementary school, college), $11 \%$ were pharmacists or pharmaceutical technical assistants, and $4 \%$ were policemen. The rest of the sample was diverse, including, for instance, insurance clerks, bank clerks, physiotherapists, secretaries, and an architect.

\section{Measures}

Participants completed a general survey and the diary booklet. In the general survey, demographic variables (e.g., age, gender, tenure, and occupation), trait mindfulness, and work demands were assessed. After completing the general survey, participants started filling in the first day of the diary booklet. To reduce commonmethod bias, predictor, mediator, and outcome variables were assessed at different time-points: sleep quality in the morning survey, mindfulness at work in the end-of-work survey, and psychological detachment in the bedtime survey. Unless otherwise indicated, responses were provided on 5-point Likert scales ranging from 1 (I fully disagree) to 5 (I fully agree). Cronbach's alphas are depicted in Table 1.

Work demands. Recovery research has revealed that work characteristics like workload or time pressure have an effect on an individual's sense of well-being before going to sleep and on other recovery-related variables (Sonnentag, 2001; Sonnentag \& Zijlstra, 2006). Researchers have therefore frequently controlled for work characteristics when investigating recoveryrelated variables like psychological detachment (e.g., Fritz et al., 2010; Sonnentag, 2003). In order to be able to control for potential confounding effects, we therefore chose to control for workload and time pressure with a German translation of the Questionnaire on the Experience and Evaluation of Work (VBBA; van Veldhoven \& Meijman, 1994; see also Bakker, Veldhoven, \& Xanthooulou, 2010). The VBBA measures quantitative work demands in terms of workload and time pressure with 11 items. A sample item is "Do you work under time pressure?"

Mindfulness. For measuring a person's overall level of trait mindfulness (general survey), we used the German version (Michalak, Heidenreich, Ströhle, \& Nachtigall, 2008) of the 15-item Mindful Attention and Awareness Scale (MAAS, Brown \& Ryan, 2003). This measure has been explicitly designed to assess mindfulness in the general population in samples with no explicit experience with mindfulness training or meditation. A sample item is "I tend to walk quickly to get where I'm going without paying attention to what I experience along the way" (reverse scored).

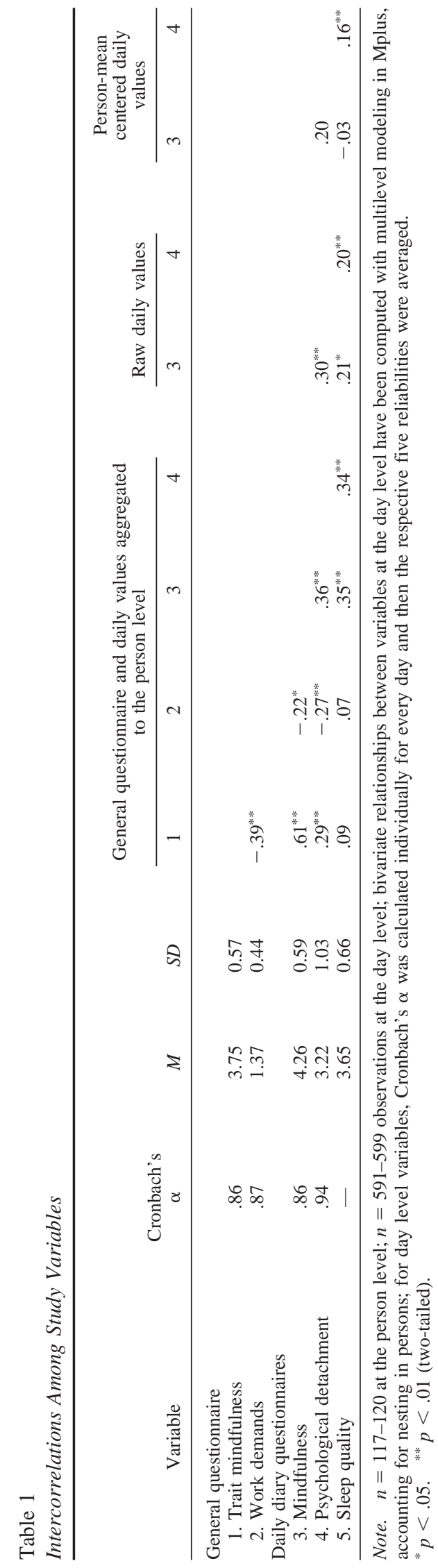


Responses were provided on a 5-point Likert scale ranging from 1 (almost never) to 5 (almost always).

Daily levels of mindfulness during work were assessed with the corresponding five-item state measure of the MAAS (Brown \& Ryan, 2003; Michalak et al., 2008): "I found it difficult to stay focused on what was happening in the present"; "I rushed through activities without being really attentive to them"; "I did jobs or tasks automatically, without being aware of what I was doing"; "I found myself preoccupied with the future or the past"; "I found myself doing things without paying attention" (all items are reversed scored).

Psychological detachment. For measuring psychological detachment from work (bedtime questionnaire), we used the German version from the respective four-item subscale of the Recovery Experience Questionnaire (Sonnentag \& Fritz, 2007): "I forgot about work"; "I did not think about work at all"; "I distanced myself from my work"; "I got a break from the demands of work."

Sleep quality. Sleep quality was reported in the morning survey and was assessed with a single item from the Pittsburgh Sleep Quality Index (Buysse, Reynolds, Monk, Berman, \& Kupfer, 1989 ) that has previously been used in similar diary studies (Sonnentag et al., 2008). "How do you evaluate this night's sleep?" was rated on a 5-point rating scale ranging from 1 (very bad) to 5 (very good).

Date and time. Participants indicated the date and time of filling in the respective diary surveys. This allowed us to code for the day of the week that a diary survey was completed.

\section{Analyses}

To exploit the hierarchical data structure (daily reports that are nested in persons), we tested hypotheses with multilevel modeling techniques: To test Hypotheses 1 and 2, we used daily assessments of (state) mindfulness, psychological detachment, and sleep quality (Level 1). Only the control variable of work demands was measured at the person level (Level 2). To test for multilevel mediation, we followed Preacher and colleagues' procedure (Preacher, Zhang, \& Zyphur, 2011; Preacher, Zyphur, \& Zhang, 2010), using multilevel structural equation modeling (MSEM) with MPlus Version 7 (Muthén \& Muthén, 1998-2012). The model we tested corresponds to a 1-1-1 mediation model (see Figure 1; Preacher et al., 2010); thus, predictor, mediator, and outcome variables were all assessed on the day level (Level 1). In contrast to traditional multilevel regression modeling using manifest (observed) variables, Level 1 predictor and mediator variables are decomposed into two uncorrelated latent variable parts in this procedure (Muthén \& Muthén, 1998-2012; for a discussion of the advantages of this approach, see Lüdtke et al., 2008). The decomposition into within-person and between-person parts is such that it "can be viewed as an implicit, latent group-mean centering of the latent within-level covariate" (p. 263; Muthén \& Muthén, 19982012). When variables are group-mean centered at Level 1 (within person), between-person variation is removed, and they are, per definition, uncorrelated with Level 2 (between-person) variables (Enders \& Tofighi, 2007). As can be seen from Figure 1 , we estimate all paths (mindfulness $\rightarrow$ detachment, detachment $\rightarrow$ sleep quality, and mindfulness $\rightarrow$ sleep quality) at both levels of analysis (within person and between person). Using

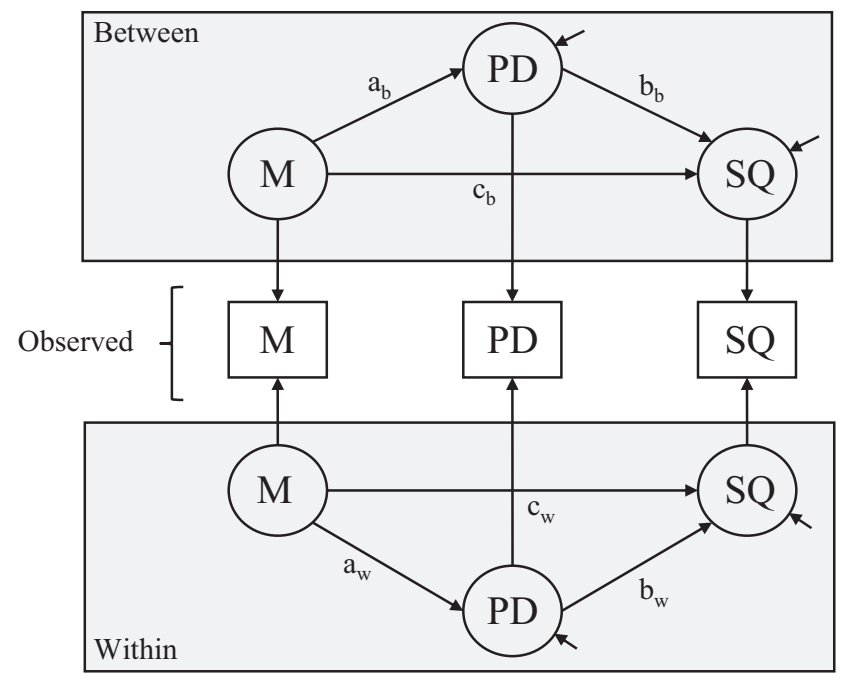

Figure 1. 1-1-1 multilevel structural equation model among day-level mindfulness (M), psychological detachment (PD), and sleep quality (SQ). Format adapted from "Alternative Methods for Assessing Mediation in Multilevel Data: The Advantages of Multilevel SEM," by K. Preacher, Z. Zhang, and M. Zypur, 2011, Structural Equation Modeling, 18, p. 167. Copyright 2011 by the Taylor \& Francis Group.

this centering scheme, coefficients indicate pure within-person relationships at Level 1 and pure between-person relationships at Level 2. The model thus provides two kinds of information: First, it informs on the role of a person's mean level of mindfulness for the average levels of psychological detachment and sleep quality (between persons, Level 2). Second, it informs on the role of a person's daily variations from his or her own mean level of mindfulness for daily psychological detachment and sleep quality (within person, Level 1). The path estimates derived in this analysis (within: $a_{w}, b_{w}$, and $c_{w}$; between: $a_{b}, b_{b}$, $\mathrm{c}_{\mathrm{b}}$; Figure 1) quantify independent relationships at the withinperson and the between-person levels and test whether they are significantly different from zero, respectively.

Yet, as outlined in the introduction, we were not only interested in independent effects at both levels of analysis but also in whether effects differ significantly between levels of analysis. The question was thus whether an emergent effect exists (Chen et al., 2005; Enders \& Tofighi, 2007; Lüdtke et al., 2008), for instance, if the mindfulness-psychological detachment relationship is stronger at the between-person than at the within-person level of analysis. To test for emergent effects, we used the approach described by Muthén and Muthén (1998-2012, pp. 262-263; also see Lüdtke et al., 2008). In doing so, we estimated additional values indicating the differences between the Level 1 and Level 2 effects $\left(a_{w} v s . a_{b}\right.$, $\mathrm{b}_{\mathrm{w}}$ vs. $\mathrm{b}_{\mathrm{b}}$, and $\mathrm{c}_{\mathrm{w}}$ vs. $\mathrm{c}_{\mathrm{b}}$; see Figure 1).

In addition to unstandardized parameters, we report standardized parameter estimates, indicating how much the outcome variable changes in standard deviation units per standard deviation change in $x$ (Muthén \& Muthén, 1998-2012), thereby providing an indication of the strengths of effects.

To test Hypotheses 3-5, we conducted growth models using random coefficient modeling (Bliese, 2006; Bliese \& Ployhart, 2002) in R using Pinheiro and Bates' (2000) nlme (linear and 
nonlinear mixed effects model) library. Accordingly, we specified growth curve models over the course of the 5 days of the study, investigating the extent to which psychological detachment and sleep quality are functions of the day of the week and mindfulness as a person-level moderator of this relationship. For this type of analysis, a measure of trait mindfulness tapping a person's general level of mindfulness was used, which was assessed in the general survey before participants started filling in the diaries. The day variable was centered on Monday, thereby providing a meaningful zero point. Work demands, mindfulness, and outcome variables were $z$ standardized in order to receive information on effect sizes. In this coding scheme, the continuous variables can be interpreted as standardized coefficients, the growth rate indicates the amount of change on the outcome variable (in $S D$ units) with each week day; interactions between the growth rate and mindfulness provide information on changes in standardized coefficients with each week day. For this set of analyses, we only included participants with regular Monday-to-Friday work schedules. Our hypotheses rested on the idea that psychological detachment and sleep quality are entrained with the work week. Since the pattern of change in psychological detachment and sleep quality between Monday and Friday is likely to be different for participants who work on weekends compared with participants who have weekends off, we only considered participants with regular work weeks. Analyses are therefore based on a somewhat smaller sample of 101 participants. ${ }^{1}$

\section{Results}

\section{Mindfulness, Psychological Detachment, and Sleep Quality at the Day Level}

Intraclass coefficients (ICC1) were estimated based on an unconditional random coefficient model in order to estimate the relative amount of between-person and within-person variance. They revealed that daily mindfulness, psychological detachment, and sleep quality displayed $47 \%, 44 \%$, and $78 \%$ of within-person variation, respectively. Intercorrelations between study variables at the between-person and at the within-person levels are depicted in Table 1. Zero-order correlations between mindfulness and psychological detachment lay between .20 and .36 , providing evidence for the distinctiveness of these empirically related constructs. Results of a multilevel analysis investigating direct relationships of mindfulness at work (assessed on a daily basis) with psychological detachment from work during non-work time and sleep quality are shown in Table 2. Relationships were analyzed both at the between-person and at the within-person levels. At the betweenperson level, mindfulness was significantly related to psychological detachment and sleep quality when a conservative two-tailed test of significance was applied. Applying a one-tailed test of significance (which is suitable when testing directional hypotheses), the relationship between mindfulness and psychological detachment was also significant at the within-person level. The data thus fully supported Hypothesis 1a while Hypothesis 1b was supported only at the between-person level. We also tested for emergent effects, thus whether relationships differed between the between-person and within-person level of analysis. Results revealed that the mindfulness-detachment and the mindfulness- sleep quality relationship were significantly stronger at the between-person level compared with the within-person level. ${ }^{2}$

Results of a multilevel mediation model testing an indirect relationship between mindfulness and sleep quality via psychological detachment (Hypothesis 2, Table 3) provided evidence for significant indirect effects of mindfulness at both levels of analysis. Further analyses of an emergent effect suggested that the indirect effect was somewhat stronger at the between-person level, although this was only significant at the $10 \%$ level. Since day of the week may cause spurious correlations in the relationship among mindfulness, psychological detachment, and sleep quality, we retested the same set of analyses including dummies controlling for day of the week at the within-person level. Including the dummies yielded the same patterns of results (see Tables 2 and 3, values in brackets). ${ }^{3}$

\section{Mindfulness and Change Trajectories in Psychological Detachment and Sleep Quality Across the Work Week}

As a first step, we tested a random intercept, fixed slope model, using weekday as a predictor of psychological detachment/sleep quality (Table 4, Model 1). In line with previous research (Fritz et al., 2010; Sonnentag, 2003), we controlled for work demands that were negatively related to psychological detachment. Intercepts indicate the mean sleep quality and psychological detachment level on a Monday.

The significant weekday slopes indicate a significant positive linear increase of psychological detachment and sleep quality over the work week, providing support for Hypotheses $3 \mathrm{~b}$ and $4 \mathrm{~b} .^{4,5}$ These models included a fixed slope; it was thus assumed that change patterns of detachment and sleep quality are constant

\footnotetext{
${ }^{1}$ Results remain virtually the same if we include the entire sample of participants and control whether participants had a regular versus irregular work week.

2 The positive work demands-sleep quality relationship reported in Table 2 is due to a suppressor effect of mindfulness (i.e., the estimate for the work demands-sleep quality relationship becomes stronger when mindfulness is included in the equation). When we performed the same analyses without mindfulness as a predictor at the between-person level, the work demands-sleep quality relationship was not significant (estimate $=.11$, $n s)$. This result is similar to the respective zero-order correlation shown in Table 1.

${ }^{3}$ Conceptually, the between-person component in such an MSEM model (i.e., a person's mean level of mindfulness across days; see Figure 1) captures the same construct as a one point in time measurement of trait mindfulness that assesses how people generally feel. We therefore tested whether using trait mindfulness (measured in the general questionnaire) as a predictor yielded results similar to those reported by testing a 2-1-1 mediation model (Preacher et al., 2010), in which trait mindfulness is used at Level 2 as a predictor of psychological detachment and sleep quality (both Level 1). Trait mindfulness had a significant direct effect on psychological detachment (estimate $=.52, p<.01$ ) but not on sleep quality (estimate $=.03, n s)$. However, the indirect effect of trait mindfulness on sleep quality via psychological detachment was significant (estimate $=.14$, $p<.05$ ), which is in line with the findings from the 1-1-1 mediation model.

${ }^{4}$ In addition to a linear increase of psychological detachment and sleep quality over the work week, we also modeled a quadratic trend. Results did, however, not provide evidence for a curvilinear change pattern (psychological detachment: estimate $=.00, n s$; sleep quality: estimate $=.00, n s$ )

${ }^{5}$ Although this was not part of our hypotheses, we tested whether state mindfulness also changed over the work week. Results did not reveal a significant weekday slope (estimate $=.00, n s$ ). There was also no indication for a curvilinear change pattern (estimate $=.02, n s$ ).
} 
Table 2

Multilevel Models Predicting Psychological Detachment After Work and Sleep Quality From Mindfulness During Working Hours

\begin{tabular}{|c|c|c|c|c|c|c|}
\hline \multirow[b]{2}{*}{ Variable } & \multicolumn{3}{|c|}{ Psychological detachment } & \multicolumn{3}{|c|}{ Sleep quality } \\
\hline & Estimate & $S E$ & $\begin{array}{l}\text { Standardized } \\
\text { estimate }\end{array}$ & Estimate & $S E$ & $\begin{array}{l}\text { Standardized } \\
\text { estimate }\end{array}$ \\
\hline \multicolumn{7}{|l|}{ Within-person level (Level 1) } \\
\hline Mindfulness & $0.20^{\dagger}\left(0.21^{\dagger}\right)$ & $0.11(0.11)$ & $.12(.12)$ & $0.01(0.02)$ & $0.14(0.14)$ & $.00(.01)$ \\
\hline Residual variance & $0.70^{* * *}\left(0.70^{* * *}\right)$ & $0.07(0.07)$ & & $0.80^{* * *}\left(0.80^{* * *}\right)$ & $0.09(0.09)$ & \\
\hline \multicolumn{7}{|l|}{ Between-person level (Level 2) } \\
\hline Intercept & $3.23^{* *}\left(2.85^{* *}\right)$ & $0.09(0.34)$ & & $3.72^{* * *}\left(3.37^{* * *}\right)$ & $0.06(0.35)$ & \\
\hline Control: work demands $\rightarrow$ outcome & $-0.46^{*}\left(-0.41^{*}\right)$ & $0.19(0.19)$ & $-.22(-.20)$ & $0.23^{\dagger}\left(0.22^{\dagger}\right)$ & $0.13(0.13)$ & $.22(.21)$ \\
\hline Mindfulness & $0.68^{* *}\left(0.65^{* *}\right)$ & $0.20(0.20)$ & $.38(.36)$ & $0.52^{\text {*** }}\left(0.51^{* *}\right)$ & $0.12(0.12)$ & $.58(.57)$ \\
\hline Emergent effect mindfulness Level 1 & & & & & & \\
\hline vs. mindfulness Level 2 & $0.48^{*}\left(0.43^{\dagger}\right)$ & $0.23(0.23)$ & & $0.51^{*}\left(0.49^{*}\right)$ & $0.05(0.20)$ & \\
\hline Residual variance & $0.71^{* *}\left(0.70^{* *}\right)$ & $0.11(0.11)$ & & $0.13^{*}\left(0.14^{*}\right)$ & $0.05(0.05)$ & \\
\hline$R^{2}$ within & $0.01\left(0.03^{\dagger}\right)$ & $0.01(0.02)$ & & $0.00(0.01)$ & $0.00(0.01)$ & \\
\hline$R^{2}$ between & $0.19^{*}\left(0.17^{*}\right)$ & $0.08(0.08)$ & & $0.39^{*}\left(0.37^{*}\right)$ & $0.16(0.15)$ & \\
\hline
\end{tabular}

Note. Models are random intercept models. Results of analyses controlling for day of the week at the within-person level are indicated in parentheses. $S E=$ standard error. Standardized estimates are indicated for path coefficients.

${ }^{\dagger} p<.05$ (one-tailed). ${ }^{*} p<.05 .^{* * *} p<.01$ (two-tailed).

among individuals. In the next step, we specified a random intercept random slope model (Model 2), thereby assuming that the relationship between workday and detachment/sleep quality varies among individuals. ${ }^{6}$ Specifically, we tested whether trait mindfulness interacted with weekday in predicting psychological detachment and sleep quality (Hypothesis 5). As expected, there was a significant cross-level interaction for psychological detachment, such that trait mindfulness explained variability in slopes between weekday and psychological detachment. Thus, variability in participants' change pattern in psychological detachment over the work week was a function of interindividual differences in mindfulness. To examine the nature of the interaction, we plotted simple slopes at 1 standard deviation above and below the mean of trait mindfulness (Aiken \& West, 1991; see Figure 2). Psychological detachment of individuals high in mindfulness remained constant over the course of the work week, while it systematically increased for individuals low in mindfulness. Testing the significance of the two simple slopes yielded a nonsignificant simple slope for individuals high on mindfulness $(+1 S D$ : estimate $=.00, n s)$ and a significant simple slope for individuals low on mindfulness $(-1 S D$ : estimate $=.13, p<.001)$. Hypothesis 5a was thus supported. In contrast, Hypothesis 5b was not supported: Mindfulness did not predict slope variability between weekday and sleep quality.

To have an indication of the strength of effects, we calculated pseudo- $R^{2}$ statistics (Raudenbush \& Bryk, 2002; Singer \& Willett, 2003; see also Thoresen, Bradley, Bliese, \& Thoresen, 2004). As can be seen from Table 5, the growth term weekday predicted $4 \%$ of within-person variation in psychological detachment, Level 2 work demands and trait mindfulness explained $22 \%$ of intercept variance (interindividual differences in participants' starting values in psychological detachment), and trait mindfulness explained about $53 \%$ of the variance in weekday slopes (interindividual differences in participants' change patterns in psychological detachment over the work week). As to sleep quality, the growth term weekday predicted about $2 \%$ of within-person variation. However, Level 2 control and predictor variables did not explain significant variance in intercept or slope variation (as can also be seen from Table 4).

\section{Discussion}

Findings of the present study contribute to the recovery literature as well as to the incipient body of research on the role of mindfulness for employee health and well-being. It does so in two ways: First, the findings provide information about the role of mindfulness for the recovery process at the day level. Second, they extend the process perspective and show change patterns of two central recovery variables and the role of mindfulness in these change patterns.

\section{The Role of Mindfulness for Psychological Detachment and Sleep Quality at the Day Level}

Taken together, findings show that the experience of mindfulness during working hours is related to subsequent sleep quality and that the ability to detach and get a psychological break from the demands of work during off-job time mediates this relationship. A comparison of relationships at the between-person and within-person levels of analysis revealed notable differences: The mindfulness-sleep quality relationship was weak and not significant at the within-person level, while it was considerable at the between-person level. Analyses of emergent effects further revealed that mindfulness-detachment and mindfulness-sleep quality relationships were significantly stronger at the between-person level than at the within-person level of analysis. These findings suggest that it is predominantly a person's general mean level of mindfulness during work that explains whether that person is able to detach and sleep well. Individual deviations from a person's own mean level seem to be less impactful in explaining daily variance in detachment and sleep quality. Simply put, whether a person is more mindful during work than he or she usually is does

\footnotetext{
${ }^{6} \mathrm{We}$ also tested for autocorrelation and for heterogeneity in error structures (Bliese, 2006). For both outcome variables, models that allowed for autocorrelation and for decreases in variance did not fit the data significantly better. We therefore proceeded with models assuming no autocorrelation and variance homogeneity.
} 
Table 3

Multilevel Mediation Models Predicting Sleep Quality From Mindfulness and Psychological Detachment

\begin{tabular}{lllr}
\hline \multicolumn{1}{c}{ Variable } & Estimate & $S E$ & $\begin{array}{c}\text { Standardized } \\
\text { estimate }\end{array}$ \\
\hline Within-person level (Level 1) & & & \\
Path $\mathrm{a}_{\mathrm{w}}$ : mindfulness $\rightarrow$ detachment & $0.20^{\dagger}\left(0.20^{\dagger}\right)$ & $0.11(0.11)$ & $.12(.11)$ \\
Path $\mathrm{b}_{\mathrm{w}}$ : detachment $\rightarrow$ sleep quality & $0.15^{* * *}\left(0.15^{* *}\right)$ & $0.06(0.06)$ & $.14(.14)$ \\
Path $\mathrm{c}_{\mathrm{w}}$ : mindfulness $\rightarrow$ sleep quality & $-0.02(-0.01)$ & $0.14(0.14)$ & $-.01(.00)$ \\
Indirect effect & $0.03^{\dagger}\left(0.03^{\dagger}\right)$ & $0.02(0.02)$ & \\
Residual variance sleep quality & $0.79^{* * *}\left(0.78^{* *}\right)$ & $0.09(0.09)$ & \\
Residual variance detachment & $0.70^{* *}\left(0.71^{* *}\right)$ & $0.07(0.07)$ & \\
Between-person level (Level 2) & & & \\
Intercept & $3.71^{* * *}\left(3.61^{* * *}\right)$ & $0.06(0.38)$ & $.42(.26)$ \\
Control: work demands $\rightarrow$ sleep quality & $0.30^{*}\left(0.26^{* *}\right)$ & $0.13(0.11)$ & $.39(.39)$ \\
Path $\mathrm{a}_{\mathrm{b}}$ : mindfulness $\rightarrow$ detachment & $0.77^{* * *}\left(0.40^{* * *}\right)$ & $0.19(0.10)$ & $.39(.40)$ \\
Path $\mathrm{b}_{\mathrm{b}}$ : detachment $\rightarrow$ sleep quality & $0.20^{* * *}\left(0.39^{* * *}\right)$ & $0.07(0.14)$ & \\
Path $\mathrm{c}_{\mathrm{b}}$ : mindfulness $\rightarrow$ sleep quality & $0.36^{* *}\left(0.40^{* * *}\right)$ & $0.13(0.14)$ & \\
Indirect effect & $0.15^{*}\left(0.14^{*}\right)$ & $0.07(0.07)$ & \\
Emergent effect $\mathrm{a}_{\mathrm{w}}$ vs. $\mathrm{a}_{\mathrm{b}}$ & $0.57^{*}\left(0.53^{*}\right)$ & $0.23(0.23)$ & \\
Emergent effect $\mathrm{b}_{\mathrm{w}}$ vs. $\mathrm{b}_{\mathrm{b}}$ & $0.05(0.05)$ & $0.10(0.10)$ & \\
Emergent effect $\mathrm{c}_{\mathrm{w}}$ vs. $\mathrm{c}_{\mathrm{b}}$ & $0.38^{\dagger}\left(0.37^{\dagger}\right)$ & $0.21(0.21)$ & \\
Emergent indirect effect & $0.12^{\dagger}(0.11)$ & $0.07(0.07)$ & \\
Residual variance sleep quality & $0.11^{*}\left(0.12^{* *}\right)$ & $0.05(0.05)$ & \\
Residual variance detachment & $0.74^{* * *}\left(0.73^{* *}\right)$ & $0.12(0.12)$ & \\
$R^{2}$ sleep quality, within & $0.02(0.03)$ & $0.02(0.02)$ & \\
$R^{2}$ sleep quality, between & $0.51^{* *}\left(0.50^{* * *}\right)$ & $0.17(0.17)$ & \\
$R^{2}$ detachment, within & $0.01(0.01)$ & $0.01(0.01)$ & \\
$R^{2}$ detachment, between & $0.18^{*}\left(0.16^{*}\right)$ & $0.08(0.08)$ & \\
\hline
\end{tabular}

Note. Models are 1-1-1 mediation models with a random intercept and fixed slopes. Paths refer to Figure 1. Results of analyses controlling for day of the week at the within-person level are indicated within parentheses. $S E=$ standard error. Standardized estimates are indicated for path coefficients.

${ }^{\dagger} p<.05$ (one-tailed). ${ }^{*} p<.05 .^{* *} p<.01$ (two-tailed).

have a smaller influence on his or her detachment and sleep quality than average mindfulness levels.

The present findings on the role of mindfulness during work for sleep quality provides information for not only the recovery but also the broader sleep quality literature. While previous research on work-related antecedents of sleep has mostly focused on workrelated factors that hinder sleep, knowledge of factors that facilitate sleep is still scarce. Although cure and prevention may look similar at first glance, they concern both different processes and research questions. In order to learn more about the factors that make some employees resilient in the face of the demands of work, researchers need to go beyond studying work-related impediments of sleep and recovery. Our findings on mindfulness, a positive psychological state, thereby also contribute to the literature on positive occupational health psychology (Bakker \& Derks, 2010). They prepare the path for researchers to develop and test the

Table 4

Growth Curve Models of Change Trajectories in Psychological Detachment and Sleep Quality Over the Work Week

\begin{tabular}{|c|c|c|c|c|c|c|c|c|c|c|c|c|}
\hline \multirow[b]{3}{*}{ Variable } & \multicolumn{6}{|c|}{ Psychological detachment } & \multicolumn{6}{|c|}{ Sleep quality } \\
\hline & \multicolumn{3}{|c|}{ Model 1} & \multicolumn{3}{|c|}{ Model 2} & \multicolumn{3}{|c|}{ Model 1} & \multicolumn{3}{|c|}{ Model 2} \\
\hline & Estimate & $S E$ & $S D$ & Estimate & $S E$ & $S D$ & Estimate & $S E$ & $S D$ & Estimate & $S E$ & $S D$ \\
\hline \multicolumn{13}{|l|}{ Fixed effects } \\
\hline Intercept (initial status) & -.12 & .09 & & -.13 & .09 & & -.15 & .09 & & -.15 & .09 & \\
\hline Work demands & $-.18^{*}$ & .08 & & -.10 & .08 & & .04 & .06 & & .08 & .07 & \\
\hline Weekday (growth rate) & $.06^{* *}$ & .02 & & $.06^{* *}$ & .02 & & $.07^{*}$ & .03 & & $.07^{*}$ & .03 & \\
\hline Trait mindfulness & & & & $.34^{* *}$ & .10 & & & & & .10 & .10 & \\
\hline Weekday $\times$ Trait Mindfulness & & & & $-.07^{* * *}$ & .02 & & & & & -.01 & .03 & \\
\hline \multicolumn{13}{|l|}{ Random effects } \\
\hline Intercept & & & .70 & & & .74 & & & .47 & & & .56 \\
\hline Weekday & & & & & & .06 & & & & & & .05 \\
\hline Residual & & & .69 & & & .67 & & & .87 & & & .87 \\
\hline
\end{tabular}

Note. $n \mathrm{~s}=100-101$ at the person level; 437-490 observations at the day level. Weekday was coded as $0=$ Monday, $1=$ Tuesday, $2=$ Wednesday, $3=$ Thursday, 4 = Friday. Work demands, trait mindfulness (assessed in the general survey), and outcome variables were $\mathrm{z}$ standardized prior to analyses. ${ }^{*} p<.05$. ${ }^{* *} p<.01$ (two-tailed). 


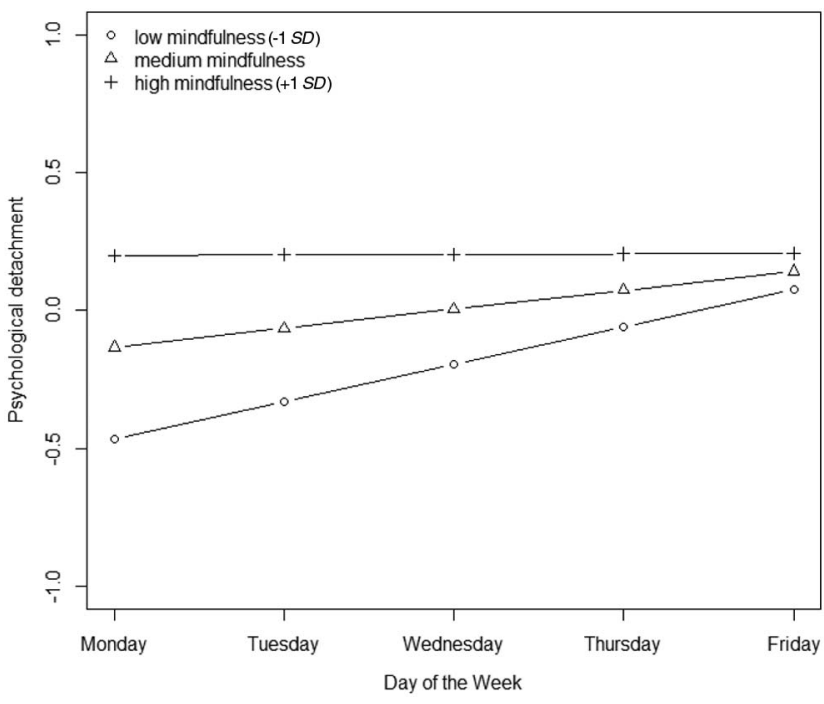

Figure 2. Psychological detachment as a function of weekday and mindfulness.

usefulness of integrating mindfulness into positive occupational health psychology interventions that focus on building competency and promoting human flourishing and well-being. Researchers have sought to develop training programs to facilitate recovery from job stress and improve employees' recovery experiences and well-being (Hahn, Binnewies, Sonnentag, \& Mojza, 2011). The present findings suggest that a mindfulness-based intervention might be a valuable addition to such training programs.

\section{Mindfulness and Change Trajectories in Psychological Detachment and Sleep Quality Across the Work Week}

Zooming in on the dynamic aspects of psychological detachment from work and sleep quality, we investigated change trajectories in psychological detachment and sleep quality over the course of the work week and individual differences therein. Results revealed that on average, participants experienced an increase in sleep quality over the Monday-to-Friday workweek. Findings thus supported Hypothesis $4 \mathrm{~b}$ rather than $4 \mathrm{a}$, suggesting decreasing levels of sleep quality. This finding is in line with the sleep quality pattern that Rook and Zijlstra's (2006) described: Although they did not statistically investigate change trajectories of sleep quality, their description of mean levels of sleep quality per weekday suggested a pattern of increasing levels of sleep quality. These findings may be explained by the fact that in the beginning of the work week, the average employee anticipates work demands and worries more about job-related issues than at the end of the week (Rook \& Zijlstra, 2006). As a consequence of increased worrying and anticipation, the employee might have poorer sleep quality in the start of the work week; sleep quality gradually increases as the work week progresses.

First and foremost, our findings inform the recovery literature by showing that psychological detachment and sleep quality are not only influenced by work characteristics, daily work events, or recovery activities but also by the work week itself. Considering these change trajectories sheds new light on previous findings: For instance, the recovery literature includes studies of the relationship between off-job activities and recovery-related variables (e.g., sleep quality and well-being at bedtime), revealing positive relationships with physical and negative relationships with workrelated activities (Rook \& Zijlstra, 2006; Sonnentag, 2001; Sonnentag \& Zijlstra, 2006). Our finding that recovery-related variables such as detachment and sleep quality are typically lowest on Monday and then increase over the work week suggests that these off-job activities may have stronger effects on recovery at the start rather than at the end of the work week: At the start of the work week, detachment and sleep quality are lowest, indicating that individuals are most vulnerable and in need for recovery. Work-related activities during off-job time may therefore be more detrimental while recovery activities (e.g., physical and social) may be more beneficial at the start than at the end of the work week.

Furthermore, our research adds to previous research exploring cyclical variation and day-of the week effects in everyday experiences. This research has, to date, focused on positive and negative affect (Beal \& Ghandour, 2011; Larsen \& Kasimatis, 1990). We extend this line of research by showing that two other phenomena are entrained with the work week. This finding broadens

Table 5

Variance Components Explained in Final Growth Models of Psychological Detachment and Sleep Quality

\begin{tabular}{|c|c|c|c|c|}
\hline \multirow[b]{2}{*}{ Model comparison } & \multicolumn{2}{|c|}{ Psychological detachment } & \multicolumn{2}{|c|}{ Sleep quality } \\
\hline & Observed variance & $\begin{array}{l}\text { Percentage of variance } \\
\text { explained (pseudo } R^{2} \text { ) }\end{array}$ & Observed variance & $\begin{array}{l}\text { Percentage of variance } \\
\text { explained (pseudo } R^{2} \text { ) }\end{array}$ \\
\hline \multicolumn{5}{|l|}{ Level 1: Within-person variation } \\
\hline Unconditional means model & .475 & & .795 & \\
\hline Unconditional growth model & & & & \\
\hline (conditional on linear weekday trend) & .457 & .039 & .778 & .021 \\
\hline \multicolumn{5}{|l|}{ Level 2: Intercept variation } \\
\hline Unconditional growth model & .712 & & .298 & \\
\hline Conditional on work demands, trait mindfulness & .555 & .221 & .315 & .000 \\
\hline \multicolumn{5}{|l|}{ Level 2: Slope variation } \\
\hline Unconditional growth model & .008 & & .004 & \\
\hline Conditional on trait mindfulness & .004 & .526 & .005 & .000 \\
\hline
\end{tabular}

Note. Unlike traditional measures of $R^{2}$ obtained from ordinary least squares regression, pseudo $R^{2}$ statistics are approximations and can have negative values. In such cases, we set the pseudo $R^{2}$ value to zero (see also Thoresen et al., 2004). 
our knowledge of the dynamic aspects of organizationally relevant variables and responds to recent calls to place more attention on time in organizational research (George \& Jones, 2000; Roe, 2008; Sonnentag, 2003).

The identification of change trajectories in detachment and sleep quality also has important methodological implications. Day of the week effects may confound findings from diary studies. Researchers should therefore try to ensure that all weekdays are equally represented in their data such that the full range of variation is captured. Furthermore, they may consider controlling for day of the week effects in their analyses (cf. Reis, Sheldon, Gable, Roscoe, \& Ryan, 2000).

It is important to note that our results lend partial support to the idea that although general patterns of change in psychological detachment and sleep quality exist across individuals, there are also individual differences in such change trajectories. While Hypothesis $5 \mathrm{~b}$ was not supported, and participants experienced a similar pattern of increasing sleep quality over the work week irrespective of their standing on trait mindfulness, Hypothesis 5a was supported: Our findings corroborated the idea that highly mindful individuals are less susceptible to the organizing power of the work week and display high levels of psychological detachment that do not systematically change over the course of the work week. This finding adds to the mindfulness literature suggesting that mindfulness promotes emotional stability and reduces emotional variability (Arch \& Craske, 2006; Brown \& Ryan, 2003; Way, Creswell, Eisenberger, \& Lieberman, 2010), which, in turn, has been shown to be associated with poorer psychological health (Gruber et al., 2013; Peeters, Berkhof, Delespaul, Rettenberg, \& Nicolson, 2006). Our aim in the present study was to investigate the role of mindfulness in explaining interindividual differences in mean-level change trajectories for psychological detachment and sleep quality over the work week. However, one may wonder whether trait mindfulness was also negatively associated with variability in psychological detachment and sleep quality. We investigated this issue in a supplementary analysis, regressing participants' standard deviation in psychological detachment/sleep quality across the 5 days on trait mindfulness, controlling for participants' mean level in detachment/sleep quality (cf. Gruber et al., 2013). Trait mindfulness was indeed negatively related to variability in psychological detachment (estimate $=-.11, p<$ .01 ), while it was unrelated to variability in sleep quality (estimate $=.03, n s)$.

\section{Limitations, Strengths, and Future Directions}

The present study should be evaluated in light of its strengths and weaknesses, which also point to areas of future research. First, our analysis of the link between mindfulness during work with sleep quality and the mediating role of psychological detachment does not allow causal conclusions to be drawn. Although we avoided the use of causal language, our theorizing and analyses imply that directions of effects are such that mindfulness precedes psychological detachment which, in turn, facilitates subsequent sleep quality. This idea is grounded in theoretical and empirical advances in the mindfulness and recovery literatures that corroborate the suggested causal ordering: Mindfulness research revealed that mindfulness-based interventions were effective in improving subsequent sleep (Carlson \& Garland, 2005; Gross et al., 2011;
Ong et al., 2012; Shapiro et al., 2003; Wolever et al., 2012) and decreasing rumination (which is inversely related to psychological detachment; Shapiro, Brown, \& Biegel, 2007; Shapiro, Oman, Thoresen, Plante, \& Flinders, 2008). Similarly, a recovery training program that targeted psychological detachment (among other elements) was shown to be effective in improving sleep quality. However, it is still possible that directions of effects may also be reversed or even reciprocal. For instance, psychological detachment may promote subsequent levels of mindfulness, and sleep quality may provide individuals with the necessary attentional resources to be more mindful and consequently serve as an antecedent to mindfulness. Our data set allowed us to test the latter hypothesis in a set of supplementary analyses, using multilevel modeling in $\mathrm{R}$ to test whether sleep quality (reported in the morning) predicted mindfulness after work controlling for morning mindfulness. Results revealed no significant effect for sleep quality (estimate $=.01, n s$ ). In contrast, a model testing mindfulness after work as a predictor of subsequent sleep quality controlling for morning sleep quality revealed a significant effect for mindfulness (estimate $=.18, p<.05$ ).

In examining change trajectories in psychological detachment and sleep quality over the course of the work week, we focused on change occurring between Monday and Friday, and we only considered participants with regular Monday-to-Friday work weeks. Future research may extend our study and include Saturdays and Sundays in order to capture and describe a full 7-day cycle, with 5 days of work and 2 days off.

A limitation of the present research lies in the fact that using paper-and-pencil surveys to collect data did not allow us to have an objective indication of the day and time that participants filled in the daily surveys. For event sampling and diary studies, different data collection modalities are available, such as handheld computers or online surveys, which all have specific advantages and disadvantages (Ohly, Sonnentag, Niessen, \& Zapf, 2010). In the present study, we chose to use paper-and-pencil surveys in order not to restrict the sample to a potentially preselected group of participants who had Internet access or basic computer/smartphone skills (cf. Ohly et al., 2010). Participants self-reported times of filling in the respective surveys provided some indication that they complied with study instructions and did indeed fill in the daily surveys separately within the instructed time frames. Ultimately, however, we cannot rule out that participants completed multiple surveys in batches, which is a notable shortcoming of our study.

In the present research, we used the trait and state version of the MAAS (Brown \& Ryan, 2003), a well-established mindfulness scale that has been explicitly developed to assess mindfulness as a natural phenomenon that can be experienced by individuals without experience with formal mindfulness meditation. It is therefore well suited for studies in the work context involving participants without meditation experience (see also Dane \& Brummel, 2014; Hülsheger et al., 2013; Reb et al., 2014). In accordance with the definition of mindfulness adopted by Brown and Ryan (2003, 2004), the MAAS is unidimensional and captures the ability and willingness to bring attention and awareness to present-moment experiences. Although mindfulness researchers agree that a present-moment orientation is the central aspect of mindfulness, there is some controversy, as to whether mindfulness measures should be confined to a present-moment orientation or whether they should extend to other aspects, the most prominent one being 
acceptance. Brown, Ryan, and colleagues (Brown \& Ryan, 2004; Brown et al., 2007; Brown, Ryan, Loverich, Biegel, \& West, 2011) posited that a nonjudgmental and accepting attitude is a natural outcome of a present-moment orientation as paying full attention to the present moment without engaging in thoughts implies that one accepts what is. Accordingly, they argued that mindfulness can best be measured as a unidimensional scale assessing a present-moment orientation and not extended to other aspects like acceptance. Others, however, see acceptance as a second, distinct element of mindfulness (Bishop et al., 2004) and argue that mindfulness is a multifaceted construct that includes acceptance and other elements (e.g., Baer, Smith, Hopkins, Krietemeyer, \& Toney, 2006; Grossman, 2011; for a comparison of different conceptualizations and measures, see also Bergomi, Tschacher, \& Kupper, 2013; Williams, Dalgleish, Karl, \& Kuyken, in press). Future research may evaluate the merit and potential differential validity of these different operationalizations of mindfulness in the context of work.

Finally, our findings illustrate the benefits of explicitly testing whether relationships differ between levels of analysis in recovery and mindfulness research. Typically, researchers using event-sampling methodology in research on organizational behavior remove between-person variance (by person-meancentering variables assessed in event-sampling studies) and focus on within-person variance exclusively. Occasionally, these findings are then compared with findings from other (e.g., crosssectional) studies that provide information on between-person relationships. Yet, as this information stems from entirely different studies, it does not allow conclusions to be drawn as to whether effects are different or comparable as this has not been statistically tested. Investigating relationships at the within-person and between-person levels simultaneously and testing for emergent effects, our study revealed that although there is a significant mindfulness-detachment relationship at both levels, the relationship is significantly stronger at the between-person level. The use of diary and event-sampling research in occupational health and organizational behavior has been growing exponentially in recent years, and important insights have been gained from acknowledging the dynamic nature of many constructs (e.g., mood, job satisfaction, performance, work engagement, and citizenship behavior) and examining relationships at the within-person level. In the future, it may be fruitful to go beyond studying processes at either the within-person or between-person level separately to consider both levels at the same time and study potential emergent effects more explicitly in research on organizational behavior in general and in occupational health research in particular (see also Bliese \& Jex, 2002; Chen et al., 2005).

\section{Conclusion}

Our research revealed that mindfulness facilitates the recovery process in two ways. At the day level, mindfulness experienced during work positively relates to psychological detachment after work and sleep quality in the following night. At the week level, our findings revealed that employees high on mindfulness are less susceptible to effects of entrainment and display constant high levels of psychological detachment over the work week. By drawing attention to the role of mindfulness in the workplace, our study goes beyond investigating causes of malfunctioning and distress at work to answer the question of what characterizes happy, resilient, and effective employees.

\section{References}

Aiken, L. S., \& West, S. G. (1991). Multiple regression: Testing and interpreting interactions. London, United Kingdom: Sage.

Åkerstedt, T., Nordin, M., Alfredsson, L., Westerholm, P., \& Kecklund, G. (2012). Predicting changes in sleep complaints from baseline values and changes in work demands, work control, and work preoccupation-The WOLF-project. Sleep Medicine, 13, 73-80. doi:10.1016/j.sleep.2011.04 .015

Allen, T. D., \& Kiburz, K. M. (2012). Trait mindfulness and work-family balance among working parents: The mediating effects of vitality and sleep quality. Journal of Vocational Behavior, 80, 372-379. doi: 10.1016/j.jvb.2011.09.002

Ancona, D. G., Okhuysen, G. A., \& Perlow, L. A. (2001). Taking time to integrate temporal research. Academy of Management Review, 26, 512 529 .

Arch, J. J., \& Craske, M. G. (2006). Mechanisms of mindfulness: Emotion regulation following a focused breathing induction. Behaviour Research and Therapy, 44, 1849-1858. doi:10.1016/j.brat.2005.12.007

Baer, R. A. (2003). Mindfulness training as a clinical intervention: A conceptual and empirical review. Clinical Psychology: Science and Practice, 10, 125-143. doi:10.1093/clipsy.bpg015

Baer, R. A., Smith, G. T., Hopkins, J., Krietemeyer, J., \& Toney, L. (2006). Using self-report assessment methods to explore facets of mindfulness. Assessment, 13, 27-45. doi:10.1177/1073191105283504

Bakker, A. B., \& Derks, D. (2010). Positive occupational health psychology. In S. Leka \& J. Houdmont (Eds.), Occupational health psychology (pp. 194-224). Chichester, United Kingdom: Wiley.

Bakker, A. B., Veldhoven, M., \& Xanthooulou, D. (2010). Beyond the demand-control model: Thriving on high job demands and resources. Journal of Personnel Psychology, 9, 3-16. doi:10.1027/1866-5888/ a000006

Beal, D. J., \& Ghandour, L. (2011). Stability, change, and the stability of change in daily workplace affect. Journal of Organizational Behavior, 32, 526-546. doi:10.1002/job.713

Bergomi, C., Tschacher, W., \& Kupper, Z. (2013). The assessment of mindfulness with self-report measures: Existing scales and open issues. Mindfulness, 4, 191-202. doi:10.1007/s12671-012-0110-9

Bishop, S. R., Lau, M., Shapiro, S., Carlson, L., Anderson, N. D., Carmody, J., . . Devins, G. (2004). Mindfulness: A proposed operational definition. Clinical Psychology: Science and Practice, 11, 230-241. doi:10.1093/clipsy.bph077

Bliese, P. D. (2006). Multilevel modeling in R (2.2): A brief introduction to $R$, the multilevel package and the nlme package. Washington, DC: Walter Reed Army Institute of Research.

Bliese, P. D., \& Jex, S. M. (2002). Incorporating a multilevel perspective into occupational stress research: Theoretical, methodological, and practical implications. Journal of Occupational Health Psychology, 7, 265276. doi:10.1037/1076-8998.7.3.265

Bliese, P. D., \& Ployhart, R. E. (2002). Growth modeling using random coefficient models: Model building, testing, and illustrations. Organizational Research Methods, 5, 362-387. doi:10.1177/109442802237116

Bohlmeijer, E., Prenger, R., Taal, E., \& Cuijpers, P. (2010). The efffects of mindfulness-based stress reduction therapy on mental health of adults with a chronic disease: A meta-analysis. Journal of Psychosomatic Research, 68, 539-544. doi:10.1016/j.jpsychores.2009.10.005

Brown, K. W., Kasser, T., Ryan, R. M., Linley, A., \& Orzech, K. (2009). When what one has is enough: Mindfulness, financial desire discrepancy, and subjective well-being. Journal of Research in Personality, 43, 727-736. doi:10.1016/j.jrp.2009.07.002

Brown, K. W., \& Ryan, R. M. (2003). The benefits of being present: Mindfulness and its role in psychological well-being. Journal of Per- 
sonality and Social Psychology, 84, 822-848. doi:10.1037/0022-3514 .84 .4 .822

Brown, K. W., \& Ryan, R. M. (2004). Perils and promises in defining and measuring mindfulness: Observations from experience. Clinical Psychology: Science and Practice, 11, 242-248. doi:10.1093/clipsy.bph078

Brown, K. W., Ryan, R. M., \& Creswell, J. D. (2007). Mindfulness: Theoretical foundations and evidence for its salutary effects. Psychological Inquiry, 18, 211-237. doi:10.1080/10478400701598298

Brown, K. W., Ryan, R. M., Loverich, T. M., Biegel, G. M., \& West, A. M. (2011). Out of the armchair and into the streets: Measuring mindfulness advances knowledge and improves interventions: Reply to Grossman (2011). Psychological Assessment, 23, 1041-1046. doi:10.1037/ a0025781

Buysse, D. J., Reynolds, C. F., Monk, T. H., Berman, S. R., \& Kupfer, D. J. (1989). Pittsburgh Sleep Quality Index (PSQI). Psychiatry Research, 28, 193-213. doi:10.1016/0165-1781(89)90047-4

Carlson, L. E., \& Garland, S. N. (2005). Impact of mindfulness-based stress reduction (MBSR) on sleep, mood, stress and fatigue symptoms in cancer outpatients. International Journal of Behavioral Medicine, 12, 278-285. doi:10.1207/s15327558ijbm1204_9

Chen, G., Bliese, P. D., \& Mathieu, J. E. (2005). Conceptual framework and statistical procedures for delineating and testing multilevel theories of homology. Organizational Research Methods, 8, 375-409. doi: $10.1177 / 1094428105280056$

Chiesa, A., \& Serretti, A. (2009). Mindfulness-based stress reduction for stress management in healthy people: A review and meta-analysis. Journal of Alternative and Complementary Medicine, 15, 593-600. doi:10.1089/acm.2008.0495

Cropley, M., Dijk, D.-J., \& Stanley, N. (2006). Job strain, work rumination, and sleep in school teachers. European Journal of Work and Organizational Psychology, 15, 181-196. doi:10.1080/13594320500513913

Dane, E., \& Brummel, B. J. (2014). Examining workplace mindfulness and its relations to job performance and turnover intention. Human Relations, 67, 105-128. doi:10.1177/0018726713487753

Davis, D. M., \& Hayes, J. A. (2011). What are the benefits of mindfulness? A practice review of psychotherapy-related research. Psychotherapy, 48, 198-208. doi:10.1037/a0022062

Enders, C. K., \& Tofighi, D. (2007). Centering predictor variables in cross-sectional multilevel models: A new look at an old issue. Psychological Methods, 12, 121-138. doi:10.1037/1082-989X.12.2.121

Etzion, D., Eden, D., \& Lapidot, Y. (1998). Relief from job stressors and burnout: Reserve service as a respite. Journal of Applied Psychology, 83, 577-585. doi:10.1037/0021-9010.83.4.577

Fritz, C., Yankelevich, M., Zarubin, A., \& Barger, P. (2010). Happy, healthy, and productive: The role of detachment from work during nonwork time. Journal of Applied Psychology, 95, 977-983. doi: $10.1037 / \mathrm{a} 0019462$

George, J. M., \& Jones, G. R. (2000). The role of time in theory and theory building. Journal of Management, 26, 657-684. doi:10.1016/S01492063(00)00051-9

Germer, C. K. (2005). What is mindfulness? In C. K. Germer, R. D. Siegel, \& P. R. Fulton (Eds.), Mindfulness and psychotherapy (pp. 1-27). New York, NY: Guilford Press.

Geurts, S. A., \& Sonnentag, S. (2006). Recovery as an explanatory mechanism in the relation between acute stress reactions and chronic health impairment. Scandinavian Journal of Work, Environment \& Health, 32, 482-492. doi:10.5271/sjweh.1053

Glomb, T. M., Duffy, M. K., Bono, J. E., \& Yang, T. (2011). Mindfulness at work. In J. Martocchio, H. Liao, \& A. Joshi (Eds.), Research in personnel and human resource management (pp. 115-157). Bingley, United Kingdom: Emerald Group.

Gosserand, R. H., \& Diefendorff, J. M. (2005). Emotional display rules and emotional labor: The moderating role of commitment. Journal of Applied Psychology, 90, 1256-1264. doi:10.1037/0021-9010.90.6.1256
Grandey, A. A., Fisk, G. M., \& Steiner, D. D. (2005). Must "service with a smile" be stressful? The moderating role of personal control for American and French employees. Journal of Applied Psychology, 90, 893-904. doi:10.1037/0021-9010.90.5.893

Groeger, J. A., Zijlstra, F. R. H., \& Dijk, D.-J. (2004). Sleep quantity, sleep difficulties, and their perceived consequences in a representative sample of some 2000 British adults. Journal of Sleep Research, 13, 359-371. doi:10.1111/j.1365-2869.2004.00418.x

Gross, C. R., Kreitzer, M. J., Reilly-Spong, M., Wall, M., Winbush, N. Y., Patterson, R., . . . Cramer-Bornemann, M. (2011). Mindfulness-based stress reduction versus pharmacotherapy for chronic primary insomnia: A randomized controlled clinical trial. Explore, 7, 76-87. doi:10.1016/ j.explore.2010.12.003

Grossman, P. (2011). Defining mindfulness by how poorly I think I pay attention during everyday awareness and other intractable problems for psychology's (re)invention of mindfulness: Comment on Brown (2011). Psychological Assessment, 23, 1034-1040. doi:10.1037/a0022713

Grossman, P., Niemann, L., Schmidt, S., \& Walach, H. (2004). Mindfulness-based stress reduction and health benefits: A meta-analysis. Journal of Psychosomatic Research, 57, 35-43.

Groth, M., Hennig-Thurau, T., \& Walsh, G. (2009). Customer reactions to emotional labor: The roles of employee acting strategies and customer detection accuracy. Academy of Management Journal, 52, 958-974. doi:10.5465/AMJ.2009.44634116

Gruber, J., Kogan, A., Quoidbach, J., \& Mauss, I. B. (2013). Happiness is best kept stable: Positive emotion variability is associated with poorer psychological health. Emotion, 13, 1-6. doi:10.1037/a0030262

Hahn, V. C., Binnewies, C., Sonnentag, S., \& Mojza, E. J. (2011). Learning how to recover from job stress: Effects of a recovery training program on recovery, recovery-related self-efficacy, and well-being. Journal of Occupational Health Psychology, 16, 202-216. doi:10.1037/a0022169

Heidenreich, T., Tuin, I., Pflug, B., Michal, M., \& Michalak, J. (2006). Mindfulness-based cognitive therapy for persistent insomnia: A pilot study. Psychotherapy and Psychosomatics, 75, 188-189. doi:10.1159/ 000091778

Hofmann, D. A., \& Gavin, M. B. (1998). Centering decisions in hierarchical linear models: Implications for research in organizations. Journal of Management, 24, 623-641. doi:10.1177/014920639802400504

Howell, A. J., Digdon, N. L., \& Buro, K. (2010). Mindfulness predicts sleep-related self-regulation and well-being. Personality and Individual Differences, 48, 419-424. doi:10.1016/j.paid.2009.11.009

Howell, A. J., Digdon, N. L., Buro, K., \& Sheptycki, A. R. (2008). Relations among mindfulness, well-being, and sleep. Personality and Individual Differences, 45, 773-777. doi:10.1016/j.paid.2008.08.005

Hublin, C., Partinen, M., Koskenvuo, M., \& Kaprio, J. (2007). Sleep and mortality: A population-based 22-year follow-up study. Sleep, 30, 12451253.

Hülsheger, U. R., Alberts, H. J. E. M., Feinholdt, A., \& Lang, J. W. B (2013). Benefits of mindfulness at work: The role of mindfulness in emotion regulation, emotional exhaustion, and job satisfaction. Journal of Applied Psychology, 98, 310-325. doi:10.1037/a0031313

Ilies, R., Scott, B. A., \& Judge, T. A. (2006). The interactive effects of personal traits and experienced states on intraindividual patterns of citizenship behavior. Academy of Management Journal, 49, 561-575. doi:10.5465/AMJ.2006.21794672

Judge, T. A., Hulin, C. L., \& Dalal, R. S. (2012). Job satisfaction and job affect. In S. W. J. Kozlowski (Ed.), The Oxford handbook of industrial and organizational psychology (pp. 496-525). New York, NY: Oxford University Press.

Kabat-Zinn, J. (1982). An outpatient program in behavioral medicine for chronic pain patients based on the practice of mindfulness meditation: Theoretical considerations and preliminary results. General Hospital Psychiatry, 4, 33-47. doi:10.1016/0163-8343(82)90026-3 
Kabat-Zinn, J. (1990). Full catastrophe living: Using the wisdom of your mind to face stress, pain and illness. New York, NY: Dell.

Kabat-Zinn, J. (1994). Wherever you go, there you are: Mindfulness meditation in everyday life. New York, NY: Hyperion.

Kessler, R. C., Berglund, P. A., Coulouvrat, C., Hajak, G., Roth, T., Shahly, V., ... Walsh, J. K. (2011). Insomnia and the performance of US workers: Results from the America Insomnia Survey. Sleep, 34, 11611171.

Klatt, M. D., Buckworth, J., \& Malarkey, W. B. (2009). Effects of lowdose mindfulness-based stress reduction (MBSR-ld) on working adults. Health Education \& Behavior, 36, 601-614. doi:10.1177/10901 98108317627

Kristeller, J. L., Baer, R. A., \& Quilian-Wolever, R. (2006). Mindfulnessbased approaches to eating disorder. In R. A. Baer (Ed.), Mindfulnessbased treatment approaches (pp. 75-91). New York, NY: Guilford Press. doi:10.1016/B978-012088519-0/50005-8

Larsen, R. J., \& Kasimatis, M. (1990). Individual differences in entrainment of mood to the weekly calendar. Journal of Personality and Social Psychology, 58, 164-171. doi:10.1037/0022-3514.58.1.164

Leroy, H., Anseel, F., Dimitrova, N. G., \& Sels, L. (2013). Mindfulness, authentic functioning, and work engagement: A growth modeling approach. Journal of Vocational Behavior, 82, 238-247. doi:10.1016/j.jvb .2013.01.012

Low, C. A., Stanton, A. L., \& Bower, J. E. (2008). Effects of acceptanceoriented versus evaluative emotional processing on heart rate recovery and habituation. Emotion, 8, 419-424. doi:10.1037/1528-3542.8.3.419

Lüdtke, O., Marsh, H. W., Robitzsch, A., Trautwein, U., Asparouhov, T., \& Muthén, B. (2008). The multilevel latent covariate model: A new, more reliable approach to group-level effects in contextual studies. Psychological Methods, 13, 203-229. doi:10.1037/a0012869

Marzuq, N., \& Drach-Zahavy, A. (2012). Recovery during a short period of respite: The interactive roles of mindfulness and respite experiences. Work \& Stress, 26, 175-194. doi:10.1080/02678373.2012.683574

Meijman, T. F., \& Mulder, G. (1998). Psychological aspects of workload. In P. J. D. Drenth \& H. Thierry (Eds.), Handbook of work and organizational psychology: Vol. 2. Work psychology (pp. 5-33). Hove, United Kingdom: Psychology Press.

Michalak, J., Heidenreich, T., Ströhle, G., \& Nachtigall, C. (2008). Die deutsche Version der Mindful Attention and Awareness Scale (MAAS): Psychometrische Befunde zu einem Achtsamkeitsfragebogen [The German version of the Mindful Attention and Awareness Scale (MAAS): Psychometric findings to a mindfulness questionnaire]. Zeitschrift für Klinische Psychologie und Psychotherapie: Forschung und Praxi, 37, 200-208. doi:10.1026/1616-3443.37.3.200

Minkel, J. D., Banks, S., Htaik, O., Moreta, M. C., Jones, C. W., McGlinchey, E. L., . . . Dinges, D. F. (2012). Sleep deprivation and stressors: Evidence for elevated negative affect in response to mild stressors when sleep deprived. Emotion, 12, 1015-1020. doi:10.1037/ a0026871

Muthén, L. K., \& Muthén, B. O. (1998-2012). Mplus user's guide (7th ed.). Los Angeles, CA: Muthén \& Muthén.

Niemiec, C. P., Brown, K. W., Kashdan, T. B., Cozzolino, P. J., Breen, W. E., \& Levesque-Bristol, C. (2010). Being present in the face of existential threat: The role of trait mindfulness in reducing defensive responses to mortality salience. Journal of Personality and Social Psychology, 99, 344-365. doi:10.1037/a0019388

Ohly, S., Sonnentag, S., Niessen, C., \& Zapf, D. (2010). Diary studies in organizational research: An introduction and some practical recommendations. Journal of Personnel Psychology, 9, 79-93. doi:10.1027/1866$5888 / \mathrm{a} 000009$

Ong, J. C., Ulmer, C. S., \& Manber, R. (2012). Improving sleep with mindfulness and acceptance: A metacognitive model of insomnia. Behaviour Research and Therapy, 50, 651-660. doi:10.1016/j.brat.2012 .08 .001
Peeters, F., Berkhof, J., Delespaul, P., Rettenberg, J., \& Nicolson, N. A. (2006). Diurnal mood variation in major depressive disorder. Emotion, 6, 383-391. doi:10.1037/1528-3542.6.3.383

Pinheiro, J. C., \& Bates, D. M. (2000). Mixed-effects models in $S$ and S-PLUS. New York, NY: Springer-Verlag. doi:10.1007/978-1-44190318-1

Preacher, K. J., Zhang, Z., \& Zyphur, M. J. (2011). Alternative methods for assessing mediation in multilevel data: The advantage of multilevel SEM. Structural Equation Modeling, 18, 161-182. doi:10.1080/ 10705511.2011.557329

Preacher, K. J., Zyphur, M. J., \& Zhang, Z. (2010). A general multilevel SEM framework for assessing multilevel mediation. Psychological Methods, 15, 209-233. doi:10.1037/a0020141

Querstret, D., \& Cropley, M. (2012). Exploring the relationship between work-related rumination, sleep quality, and work-related fatigue. Journal of Occupational Health Psychology, 17, 341-353. doi:10.1037/ a0028552

Raudenbush, S. W., \& Bryk, A. S. (2002). Hierarchical linear models (Vol. 2). Thousand Oaks, CA: Sage.

Reb, J., Narayanan, J., \& Chaturvedi, S. (2014). Leading mindfully: Two studies on the influence of supervisor trait mindfulness on employee well-being and performance. Mindfulness, 5, 36-45. doi:10.1007/ s12671-012-0144-Z

Reb, J., Narayanan, J., \& Ho, Z. W. (2013). Mindfulness at work: Antecedents and consequences of employee awareness and absentmindedness. Mindfulness. Advance online publication. doi:10.1007/ s12671-013-0236-4

Reis, H. T., Sheldon, K. M., Gable, S. L., Roscoe, J., \& Ryan, R. M (2000). Daily well-being: The role of autonomy, competence, and relatedness. Personality and Social Psychology Bulletin, 26, 419-435. doi $10.1177 / 0146167200266002$

Roe, R. (2008). Time in applied psychology. European Psychologist, 13, 37-52. doi:10.1027/1016-9040.13.1.37

Rook, J. W., \& Zijlstra, F. R. H. (2006). The contribution of various types of activities to recovery. European Journal of Work and Organizational Psychology, 15, 218-240. doi:10.1080/13594320500513962

Segal, Z., Williams, M. R., \& Teasdale, J. (2002). Mindfulness-based cognitive therapy for depression: A new approach to preventing relapse. New York, NY: Guilford Press.

Shapiro, S. L., Bootzin, R. R., Figueredo, A. J., Lopez, A. M., \& Schwartz, G. E. (2003). The efficacy of mindfulness-based stress reduction in the treatment of sleep disturbance in women with breast cancer: An exploratory study. Journal of Psychosomatic Research, 54, 85-91. doi: 10.1016/S0022-3999(02)00546-9

Shapiro, S. L., Brown, K. W., \& Biegel, G. M. (2007). Teaching self-care to caregivers: Effects of mindfulness-based stress reduction on the mental health of therapists in training. Training and Education in Professional Psychology, 1, 105-115. doi:10.1037/1931-3918.1.2.105

Shapiro, S. L., Carlson, L. E., Astin, J. A., \& Freedman, B. (2006). Mechanisms of mindfulness. Journal of Clinical Psychology, 62, 373386. doi: $10.1002 /$ jclp. 20237

Shapiro, S. L., Oman, D., Thoresen, C. E., Plante, T. G., \& Flinders, T (2008). Cultivating mindfulness: Effects on well-being. Journal of Clinical Psychology, 64, 840-862. doi:10.1002/jclp.20491

Singer, J. D., \& Willett, J. B. (2003). Applied longitudinal data analysis: Modeling change and event occurrence. New York, NY: Oxford University Press.

Sonnentag, S. (2001). Work, recovery activities, and individual well-being: A diary study. Journal of Occupational Health Psychology, 6, 196-210. doi:10.1037/1076-8998.6.3.196

Sonnentag, S. (2003). Recovery, work engagement, and proactive behavior: A new look at the interface between nonwork and work. Journal of Applied Psychology, 88, 518-528. doi:10.1037/0021-9010.88.3.518 
Sonnentag, S., \& Binnewies, C. (2013). Daily affect spillover from work to home: Detachment from work and sleep as moderators. Journal of Vocational Behavior, 83, 198-208. doi:10.1016/j.jvb.2013.03.008

Sonnentag, S., Binnewies, C., \& Mojza, E. J. (2008). Did you have a nice evening? A day-level study on recovery experiences, sleep, and affect. Journal of Applied Psychology, 93, 674-684. doi:10.1037/0021-9010 93.3.674

Sonnentag, S., \& Fritz, C. (2007). The Recovery Experience Questionnaire: Development and validation of a measure. Journal of Occupational Health Psychology, 12, 204-221. doi:10.1037/1076-8998.12.3 .204

Sonnentag, S., \& Zijlstra, F. R. H. (2006). Job characteristics and off-job activities as predictors of need for recovery, well-being, and fatigue. Journal of Applied Psychology, 91, 330-350. doi:10.1037/0021-9010 .91 .2 .330

Thoresen, C. J., Bradley, J. C., Bliese, P. D., \& Thoresen, J. D. (2004). The Big Five personality traits and individual job performance. Journal of Applied Psychology, 89, 835-853. doi:10.1037/0021-9010.89.5.835

van Veldhoven, M., \& Meijman, T. F. (1994). Het meten van psychosociale arbeidsbelasting met een vragenlijst: De Vragenlijst Beleving en Beoordeling van de Arbeid (VBBA) The measurement of psychosocial strain at work: [Questionnaire on the Experience and Evaluation of Work]. Amsterdam, the Netherlands: Nederlands Instituut voor Arbeidsomstandigheden.

Walkowiak, A. L. T., Hülsheger, U. R., \& Zijlstra, F. R. H. (2010). De relatie tussen herstel, werkdruk, en slaap: Een dagboekstudie (The relationship between recovery, work pressure, and sleep: A diary study). Gedrag en Organisatie, 23, 316-323.

Watson, D. (2000). Mood and temperament. New York, NY: Guilford Press.
Way, B. M., Creswell, D., Eisenberger, N. I., \& Lieberman, M. D. (2010) Dispositional mindfulness and depressive symptomatology: Correlations with limbic and self-referential neural activity during rest. Emotion, 10, 12-24. doi:10.1037/a0018312

Weinstein, N., Brown, K. W., \& Ryan, R. M. (2009). A multi-method examination of the effects of mindfulness on stress attribution, coping, and emotional well-being. Journal of Research in Personality, 43, 374385. doi:10.1016/j.jrp.2008.12.008

Williams, M. J., Dalgleish, T., Karl, A., \& Kuyken, W. (in press). Examining the factor structures of the Five-Facet Mindfulness Questionnaire and the Self-Compassion Scale. Psychological Assessment. doi:10.1037/ a0035566

Wolever, R. Q., Bobinet, K. J., McCabe, K., Mackenzie, E. R., Fekete, E. Kusnick, C. A., \& Baime, M. (2012). Effective and viable mind-body stress reduction in the workplace: A randomized controlled trial. Journal of Occupational Health Psychology, 17, 246-258. doi:10.1037/ a0027278

Zhang, J., Ding, W., Li, Y., \& Wu, C. 2013. Task complexity matters: The influence of trait mindfulness on task and safety performance of nuclear power plant operators. Personality and Individual Differences, 55, 433439. doi:10.1016/j.paid.2013.04.004

Zijlstra, F. R. H., Cropley, M., \& Rydstedt, L. W. (2014). From recovery to regulation: An attempt to reconceptualize "recovery from work." Stress and Health, 30, 244-252. doi:10.1002/smi.2604

Received July 26, 2013

Revision received July 7, 2014

Accepted July 14, 2014

\section{Call for Nominations}

The Publications and Communications (P\&C) Board of the American Psychological Association has opened nominations for the editorships of Developmental Psychology and the Journal of Consulting and Clinical Psychology for the years 2017-2022. Jacquelynne S. Eccles, PhD, and Arthur M. Nezu, PhD, respectively, are the incumbent editors.

Candidates should be members of APA and should be available to start receiving manuscripts in early 2016 to prepare for issues published in 2017. Please note that the P\&C Board encourages participation by members of underrepresented groups in the publication process and would particularly welcome such nominees. Self-nominations are also encouraged.

Search chairs have been appointed as follows:

- Developmental Psychology, Suzanne Corkin, $\mathrm{PhD}$, and Mark Sobell, $\mathrm{PhD}$

- Journal of Consulting and Clinical Psychology, Neal Schmitt, PhD, and Annette LaGreca, $\mathrm{PhD}$

Candidates should be nominated by accessing APA's EditorQuest site on the Web. Using your Web browser, go to http://editorquest.apa.org. On the Home menu on the left, find "Guests." Next, click on the link "Submit a Nomination," enter your nominee's information, and click "Submit."

Prepared statements of one page or less in support of a nominee can also be submitted by e-mail to Sarah Wiederkehr, P\&C Board Search Liaison, at swiederkehr@apa.org.

Deadline for accepting nominations is January 7, 2015, when reviews will begin. 